\title{
TEKNO-CULTURE: MEMAHAMI KONDISI MASYARAKAT MASA DEPAN
}

\author{
A s w a n \\ Institut Agama Islam Negeri (IAIN) Palopo \\ Email: azwan.lingkar@gmail.com
}

\begin{abstract}
The development of advanced communications technology has brought about fundamental changes in the world of life. A number of views on the spirit behind the progress are emerging, as well as about the effects it incurs. This paper tries to see two basic things. First about the passion and trends behind the advances in communication technology. This section includes all-free behavior that encourages the tendency of abnormalities, identity greed, the speed and interconnectedness. Second, about the spirit of thought that underlies the advancement of communication technology. This section reviews the three currents of thought that become the dominant discusus in viewing technology. That thought is; 1) utopianism as an optimistic view of the positive role of science and technology, 2) dystopianism, as a pessimistic view of science and technology, and 3) hypertopianism, as the 'fatalist' view of science and technology. The various streams of thought that the author studied from a number of literatures in this field show the tendency of many thinkers to highlight the negative aspects of the latest advances in communication technology. Similarly depicted in this paper, the gloomy portrayal of the future of communication technology in this paper can be viewed positively, that it gives us a map of the spirit of progress, as a "long-warning system" that provides mapping, and the possibility of the future by departing from current social, cultural and technological trends can help us read its constellations and impacts
\end{abstract}

Keywords: Culture, Comunication, Tecnology

\begin{abstract}
Abstrak
Perkembangan teknologi komunikas mutakhir telah mengusung berbagai perubahan fundamental pada dunia kehidupan. Sejumlah pandangan tentang semangat dibalik kemajuan tersebut bermunculan, juga tentang efekyang ditumbulkannya. Tulisan ini mencoba melihat dua hal mendasar. Pertama, tentang semangat dan kecenderungan dibalik kemajuan teknologi komunikasi itu. Bagian ini mencakup prilaku serba bebas yang mendorong kecenderungan abnormalitas, kegamangan identitas, kecepatan dan kesaling-terhubungan. Kedua, tentang semangat pemikiran yang mendasari kemajuan teknologi komunikasi tersebut. Bagian ini mengulas tiga arus pemikiran yang menjadi diskusus dominan dalam melihat teknologi. Pemikiran tersebut adalah; 1) utopianisme (utopianism) sebagai pandangan optimis tentang peran positif sains dan teknologi, 2) distopianisme (dystopianism), sebagai pandangan pesimis tentang sains dan teknologi, dan 3) 'hiper-topianisme' (hypertopianism), sebagai pandangan 'fatalis' tentang sains dan teknologi. Berbagai arus pemikiran yang diteliti penulis dari sejumlah literatur dalam bidang ini memperlihatkan kecendrungan para pemikir lebih banyak menyoroti aspek negatif dari kemajuan teknologi komunikasi mutakhir. Demikian pula tergambar dalam tulisan ini, penggambaran masa depan yang suram tentang teknologi komunikasi dalam tulisan ini bisa dilihat positif, bahwa, ia memberikan kita sebuah peta dari semangat kemajuan itu, sebagai sebuah "sistem peringatan jauh-jauh hari" yang memberikan pemetaan, ramalan, dan kemungkinan masa depan dengan berangkat dari tren sosial budaya dan teknologi masa kini dapat membantu kita membaca konstelasi dan dampaknya.
\end{abstract}

Kata Kunci: Budaya, Komunikasi, Teknologi. 


\section{PENDAHULUAN}

Sejarah perkembangan sains dan teknologi memang selalu dihiasi oleh wacana-wacana kritis menyangkut efek dan pengaruhnya terhadap masa depan dunia kehidupan. Sejak pertengahan abad ke 19 hingga kini, beberapa pemikir, mulai Baudellaire, Tolstoy, Sorokin, hingga Heidegger, Adorno dan Virilio telah membentangkan berbagai gambaran suram sains dan teknologi, yang dilihat telah menciptakan berbagai masalah kemanusiaan, degradasi peradaban, dan penghancuran diri sendiri umat manusia (self destruction). Meskipun demikian, tidak sedikit pula pemikir-pemikir lain yang bersikap lebih optimis terhadap perkembangan sains dan teknologi. ${ }^{1}$

Pergeseran paradigma yang terjadi dipenghujung abad ke 19 telah mendesakkan berbagai visi baru yang telah mengugat berbagai teori-teori lama dalam tradisi ilmu pengetahuan. Ada banyak fenomena-fenomena baru dalam kehidupan yang memaksa kita menjelaskan kembali lingkungan sosial dan budaya kita. Kemajuan teknologi informasi dan komunikasi misalnya membuat kita mempertanyakan kembali segala sesuatu yang selama ini telah kita simpulkan ${ }^{2}$ Teori determinisme teknologi (Theory of Technological Determinism) menjadi penjelas dari berbagai perubahan relitas budaya kehidupan manusia. Dengan teknologi itulah dirajut pola-pola kehidupan baru dan menampilkan realitas yang juga sama sekali baru.

Sebenarnya, hari ini tanpa sadar kita telah terlibat dalam simulasi sebuah tatanan ruang sosial baru. Sebuah medan fenomenologis dan ontologis yang telah terbentang luas berada di hadapan kita; yaitu sebuah ruang sosial baru (Masyarakat virtual dalam dunia jejaring sosial) yang tidak lagi mengikuti hukum fisika Newtonian, dimana ruang tersebut telah menghasilkan rajutan kehidupan sehari-hari, mendominasi waktu kita, membentuk pandangan-pandangan politik dan sikap sosial kita, dan memberikan berbagai bahan yang digunakan untuk membentuk identitas pribadi dan budaya baru³ (Martin Heidegger, 1995:56).

Prinsip-prinsip fundamental yang selama ini menjadi pondasi yang membentuk sebuah masyarakat seperti identitas personal, identitas kultural, dan struktur sosial juga menjadi karakteristik dalam ruang jejaring Media Sosial. Komponen-komponen sosial di dalam ruang sosial (social space) yang nyata (real) sama persis dengan ruang sosial dalam masyarakat virtual (virtual social space). Di dalamnya setiap orang bersenda gurau, berdebat, berdagang, menyusun rencana, mendapatkan hiburan, mencari kesenangan, bertukar pengetahuan, memberikan dorongan emosional, bergosip, bertengkar, protes,

${ }^{1}$ Yaraf Amir Piliang, Sastra dalam Hiper Sains, Jakarta, Harian Kompas, 3 Agustus 2017

2 Marshall McLuhan, Understanding Media: The Extensions Of Man, Routledge Classics, London, 1964, hal 248

${ }^{3}$ Martin Heidegger, The Age of the World Picture 1995, hal 56 
mengkritik, mencari teman, mencari pacar, dan bahkan jatuh cinta. Sebuah budaya baru telah hadir, dari teknologi kemonukasi itu dihasilkan rajutan kehidupan sehari-hari ${ }^{4}$. Ia mendefinisikan apa yang baik dan buruk, positif atau negatif, bermoral atau biadap. Teknologi komunikasi telah menjadi sumber makna, mitos yang membantu terbentuknya budaya bersama dalam dunia kehidupan (live world), (yang dalam tulisan ini kemudian disebut TeknoCulture).

Penggunaan teknologi komuniasi berjalan seiring dengan masa depan yang dibentuknya, sebuah momentum dari kemajuan teknologi komunikasi yang mentransformasikan masyarakat di dunia menjadi sebuah satuan komunitas global tanpa dinding pembatas seperti ideologi politik, agama, dan nasionalitas, yang ia sebut sebagai "kampung global" 5 Teknologi yang selama ini dituduh sebagai penyebab desosialisasi dalam kehidupan masyarakat moderen, kini tampil sebagai ruang sosialisasi baru yang begitu efektif menjalin berbagai relasi-relasi sosial. Media Sosial misalnya kini tampil memainkan sebuah "simulasi kehidupan" tanpa memandang batas-batas terotorial. Seseorang boleh jadi lebih dekat secara sosial dengan seseorang yang jauh secara teritorial, ketimbang seseorang yang dekat secara teritorial, akan tetapi jauh secara sosial. ${ }^{6}$

Dunia yang dibentuk oleh teknologi adalah sebuah dunia kehidupan (live world) yang terbentuk akibat interaksi manusia dengan teknologi tersebut. Implikasinya, hadirlah sebuah bentuk "pembentangan kemungkinan dunia" (possible world) atau sebuah "perluasan medan pengalaman" (field of experience). Melalui sains dan teknologi "dibentangkan" sebuah dunia yang belum pernah ada, belum terbayangkan atau belum terimajinasikan sebelumnya. Akan tetapi, pembentangan sains dan teknologi adalah pembentangan penuh ambiguitas. Di satu pihak, sains dan teknologi membentangkan semacam horizon pengharapan (horizon of expectation): pengembaraan tak bertepi, pengetahuan tanpa batas, pengalaman tanpa pembatas. Di pihak lain, ia menciptakan pula "ketakterlukisan yang enigmatik", "kecemasan yang tanpa akhir" (anxiety), "rasa ketakamanan ontologis" (ontological insecurity), "keterserapan dan kecanduan", serta "ketakpastian identitas dan subyektivitas"7

\footnotetext{
${ }^{4}$ Douglas Kellner, Media Culture: Cultural Studies, Indentitu and Politics between the Moderen and the Postmodern, London and New York, Routledge, 1995, hal 1

${ }^{5}$ McLuhan, Understanding Media: The Extensions Of Man, Routledge Classics, London, 1964, hal 248

6 Yasraf Amir Piliang, Post-Realitas; Realitas Kebudayaan dalam Era Post-Metafisika, Penerbit Jalasutra, Yogyakarta, 2004, hal 40 2017, hal 1

7 Yaraf Amir Piliang, Sastra dalam Hiper Sains, Jakarta, Harian Kompas, 3 Agustus
} 
Ada beberapa aspek fundamental yang mendasari pergeseran budaya lama ke budaya baru. Pertama Perayaan Abnormalitas, Kedua Kegamangan Indentitas, dan Ketiga Kecepatan dan Connectivity

\section{PERAYAAN ABNORMALITAS}

Impotennya teori-teori lama dalam menjelaskan fenomena masyarakat kontemporer yang syarat dengan teknologi, sehingga teori-teori yang lahir dari rahim modernisme kehilangan akurasinya. Menyingsingnya senja modernisme disusul kemunculan fajar Postmodernisme yang menyediakan cara pembacaan baru dan sama sekali lain terhadap fenomena masyarakat kontemporer. Kehadiran cara berpikir postmodernisme secara konseptual seiring dengan munculnya berbagai hal-hal baru, lain dan bahkan aneh dalam kehidupan masyarakat. Aktifitas keseharian masyarakat Tekno-Culture telah membuat patahan, keterputusan dengan tradisi lama. Muncul budaya baru dan makna baru yang tidak pernah dijumpai dimasa lalu. Segalanya telah terjungkir balik, kata Baudrillard. "Satu-satunya kenikmatan sejati di dunia ini adalah untuk menyaksikan segala sesuatu 'berbalik' menjadi bencana, untuk akhirnya keluar dari determinasi dan indeterminasi, dari peluang dan keniscayaan, dan memasuki kenyataan tentang keterkaitan yang memusingkan dimana, suka atau tidak suka, segala sesuatu sampai pada akhirnya tanpa melalui cara-caranya, dimana kejadian-kejadian menghasilkan efek tanpa melalui penyebabnya" 8

Runtuhnya budaya lama, kaburnya batas antara normalitas dan abnormalitas, menandakan tampilnya berbagai budaya subculture yang selama ini terpinggirkan. Berbagai gaya dan identitas yang dibangun oleh subkultur, homo seksual. kelompok kulit hitam adalah anti tesis terhadap klaim-klaim universalitas kebudayaan. Penyimpangan dari normalitas, dilanggarnya segala tabu, permainan bebas, persilangan gaya, hibriditas makna menawarkan pengalaman-pengalaman baru yang mengairahkan, mencemaskan sekaligus menakutkan. Konsekuensinya, hal ini membuka kebebasan bagi pemutarbalikan nilai. Gaya-gaya yang ditawarkan subkultur, kelompok feminis, kaum gay, misalnya, telah menjadikan yang abnormal menjadi normal, demikian juga sebaliknya. ${ }^{9}$

Kehidupan masyarakat Tecno-Culture ini sesungguhnya adalah sebuah panggung tempat segalah hal yang serba terbalik dipertunjukkan; mulai dari fenomena jubah, jilbab, dan purdah sampai pada catut marut cat rambut, wajah plastik, kuku palsu, dan asesoris erotis; mulai dari ketekunan wacana pencarian ilmu di madrasah, kekhusukan di tempat ibadah, dan keheningan

${ }^{8}$ Jean Baudrillard; Beyond the Vanishing Point of Art," terj. Paul Foss, dalam P. Taylor, ed., Post-Pop Art, Cambridge: MIT, 1987, 1989

9 Yasraf Amir Piliang, Merayakan Abnormalitas: Identitas di Zaman Pluralisme Kebudayaan, dalam Jurnal Kalam, Jakarta 1995, hal 90 
masjid, sampai pada kegilaan di tempat-tempat hiburan, kekerasan di jalanan, riuh rendah supermarket, sorak-sorai televisi, hingar-bingar sebuah musik rock, dan deru derai sebuah sirkuit. ${ }^{10}$ Bagaimanakah dua fenomena yang kontradiksi seperti kekhusukan/kehingarbingaran, kesalehan/kegilaan dapat disatu-padukan dan dihadir bersamaan dalam satu medium yang digerakkan oleh kecanggihan teknologi komunikasi. Inilah yang disebut Jean Baudrillar sebagai kefatalan dimana segala sesuatu 'berbalik' menjadi bencana, untuk akhirnya keluar dari determinasi dan indeterminasi, dari peluang dan keniscayaan, dan memasuki kenyataan tentang keterkaitan yang memusingkan. ${ }^{11}$

Karena segala fasilitas Teknologi Komunikasi mampu memudahkan apa saja, dengan copy paste, penopengan, pemutarbalikan dan pembajakan, kategori-kategori "normal" dan "menyimpang" melebur. Dengan sangat mudah, siapa saja bisa mengandakan identitasnya, menormalkan sesuatu yang abnormal, mensubversi dari kode-kode sosial yang mapan. Ini membutikan apa yang dikatakan Julia Kristeva sebagai "perversi", yaitu mengaburnya segala sesuatu. Dalam perversi kebudayaan dan seni, pelanggaran kaidah, pembalikan norma, perusakan tata bahasa, pengacauan prosedur, pemutarbalikan bahasa, pembajakan identitas menjadi seakan-akan normal, disebabkan melemahnya kekuatan hukum dan tabu. Pelanggaran dan abnormalitas kini bukan dianggap sebagai satu kesalahan, akan tetapi keberanian. Bahkan pelanggaran tabu tidak lagi dianggap sebagai dosa, akan telapi sebaliknya. menjadi satu bentuk kenikmatan. ${ }^{12}$

\section{KEGAMANGAN IDENTITAS}

Kecangihan Teknologi Komunikasi telah mengaburkan identitas, dan mengelabui realitas. Misalnya, pencurian citra maskulinitas oleh kaum wanita dan begitu pula sebaliknya (baca Lesbi Gay Bencong Trans Gender) menyebabkan hancurnya integritas dan orisinalitas keduanya. Dan kini, kita dihadapkan dengan wajah dunia penampakan yang dihiasi dengan realitas simulasi dan identitas palsu, dalam model estetika perversitas, obyek-obyek estetik diproduksi dan direproduksi berdasarkan prinsip "antirealitas", "antiidentitas", dan "hibriditas".13

Hibriditas, dalam pengertian kultural. Merupakan sistem kebudayaan tertutup, yang didalamnya elemen-elemen yang sebetulnya mengandung bentrok identitas yang berbeda secara diametral, secara pasti meleburkan

\footnotetext{
10 ibid., 1995, hal 95

${ }^{11}$ Jean Baudrillard, Beyond the Vanishing Point of Art," terj. Paul Foss, dalam P. Taylor, ed., Post-Pop Art, Cambridge: MIT, 1987

12 Yasraf Amir Piliang, Merayakan Abnormalitas: Identitas di Zaman Pluralisme Kebudayaan, dalam Jurnal Kalam, Jakarta 1995, hal 97

13 Ibid., hlm 97
} 
kontras mereka dalam upaya (re)produksi sebuah kesatuan lebih tinggi yang bersifat eksternal terhadap mereka. ${ }^{14}$ Hibriditas membawa identitas asal yang orisinil, namun membawanya dalam benluk yang tidak orisinil lagi takkala ia dikawinkan dengan identitas lain. Akibatnya, eksotisme dan orisinalitas yang menjadi ciri khas identitas dan kebudayaan lama tidak bisa lagi dipertahankan, ia tidak akan mampu bertahan dari cengkraman teknologi komunikasi global yang akan mengusik dan mempengaruhi keutuhan, integritas dan orisinalitasnya. Setiap yang eksotis dan orisinal pada akhirnya akan terjamah oleh teknologi, citra, tontonan, dan komoditi kapitalisme global.

\section{KECEPATAN DAN CONNECTIVITY}

Merenung, refleksi mendalam, dan kontemplasi adalah sebuah pekerjaan yang membutuhkan waktu lama. Biasanya, untuk mengambil sebuah keputusan berat, sulit dan strategis dibutuhkan ketiga hal diatas. Kini, di zaman Tekno-Culture, berpikir lama dianggap membuang-buang waktu. Tua harus diganti dengan yang muda, yang lambat akan disingkirkan oleh yang cepat. Akibatnya, tempat-tempat perawatan wajah dan pusat-pusat kebugaran bermunculan dimana-mana untuk "menunda" penuaan. Para produsen teknologi memperbaharui produk mereka setiap bulan karena takut produknya lambat ketimbang produk saingan. Segalanya berpacu menjadi yang tercepat. Satu-satunya kepercaaan yang dipegang adalah peralihan dari satu bentuk kebentuk yang lain secara konstan dan tanpa henti. Siapa cepat dia dapat, yang lambat akan musnah.

Keharusan beralih dari suatu benda ke benda lain merupakan satu manifestasi dari sistem kapitalisme. Segalanya harus bergerak dengan cepat; mesin harus berputar, modal harus bergerak, stok harus diganti, Display picture BBM harus diperbaharui, recent update harus di cek, pakaian mesti selalu baru dan seterusnya. ${ }^{15}$ Kepanikan masyarakat Tekno-Culture adalah kepanikan terhadap kecepatan. Semuanya ditinggalkan dibelakang tanpa bekas, kecuali obsesi akan kecepatan. Konsekuensi fatal akan obsesi terhadap kecepatan adalah hilangnya perenungan, refleksi dan kontemplasi dalam budaya dan prilaku manusia. Misalnya, makanan harus cepat saji, keputusan harus cepat diambil, anak harus cepat besar, tugas harus cepat selesai, berita harus cepat dikirim dan seterusnya. Makna dan kedalaman digusur kepanikan dan kedangkalan. Ketelitian, kreativitas, dan akal budi mendapat batu ujian. Masyarakat lebih ingin membeli daripada membuat. Bila tak membeli dalam sehari seseorang belum dapat menjadi anggota masyarakat konsumer sejati,

\footnotetext{
14 Ibid., hlm 98

15 Yasraf Amir Piliang, Tamasya Diantara Keping-Keping Masa Lalu, Titik Balik Modernitas, dalam Jurnal Kalam, Jakarta 1994, hal 106
} 
bila membuat sendiri akan dianggap membeku dan terbelakang seperti sedang tidur panjang dalam keadaan koma.

Bersamaan dengan kecepatan, masyarakat Tekno Culture juga senantiasa terhubung satu sama lain. Kondisi saling terhubung (Conectivity) memungkinkan interaksi komunikasi yang tanpa batas membuat individu membangun berbagai relasi dengan siapa saja, dimana saja, dan kapan saja. Conectivity memungkinkan terjalinnya interaksi dalam berbagai bentuk. Kondisi serba terhubung dan harus terhubung ini meniscayakan lahirnya budaya narsisme dan selfisme: Status di media sosial harus segera di share, foto baru harus segera di pamer, Timeline harus senantiasa dipantau, display picture BBM harus diperbaharui, recent update harus selalu di cek. Pernyataan diri (self expression), relasi diri (self relation), dan mobiliasi diri (self mobilitation), dengan leluasa bergerak mencari pelepasan dan pelampiasan. Katub tabu dan segala hal rahasia dilepas ke publik. Tak ada lagi misteri, segalanya tranparan. ${ }^{16}$

\section{KONDISI MASYARAKAT MASA DEPAN}

Beberapa dasawarsa belakangan ini kita menyaksikan migrasi besarbesaran ummat manusia dari dunia nyata ke dunia maya. Sejak ditemukannya Facebook tahun 2004 silam yang disusul dengan banyak media sosial serupa setelahnya, menandakan perkembangan penting dalam teknologi yang akan menghasilkan tatanan dunia kehidupan yang sama sekali lain. Penemuanpenemuan penting ini memberikan kita suatu arkeologi masa depan untuk menjelaskan struktur, kecenderungan, dan dinamika masa kini. Sebuah "sistem peringatan jauh-jauh hari" yang memberikan pemetaan, ramalan, prediksi, dan kemungkinan masa depan dengan berangkat dari tren sosial, budaya dan teknologi masa kini dapat membantu kita membaca konstelasi, situasi dan dampaknya. Ini dapat memberi kita kemampuan mengatasi guncangan di masa depan ketika perubahan radikal dalam kebudayaan terjadi di depan mata. ${ }^{17}$ Meminjam metafora Baudrillard, ketika segala sesuatunya telah dipecahkan ilmu pengetahuan, batas paling akhir telah diterobos, wilayah yang paling jauh telah dijelajahi, semua ruang telah ditaklukkan, semua imajinasi dan mimpi telah jadi kenyataan, tiba-tiba, kata Baudrillar, kita meninggalkan dunia real dibelakang dan tiba-tiba realitas menghilang dari pandangan kita. Bukan menghilang ke dalam ketiadaan tapi ke dalam sesuatu yang lebih nyata dari kenyataan itu sendiri (Hyper-Realitas). Dan, bagaimana

${ }^{16}$ Aswan, Social Control and New Media: A Study of the use of Facebook by the Student of Makassar to Control the Public Policy, Tesis Pasca Sarjana di Universitas Hasanuddin, Makassar, 2011, hal 17

17 Douglas Kellner, Media Culture: Cultural Studies, Indentitu and Politics between the Moderen and the Postmodern, London and New York, Routledge, 1995, hal 426 
jika teknologi komunikasi masyarakat moderen menceburkan kita bukan ke dalam chaos tapi ke dalam kejenuhan makna yang maha hebat? bagaimana jika kedalaman makna tak ada lagi, semuanya hanya permukaan belaka? dan bagaimana jika semua tidak lagi menarik dan sekaligus tidak membuat jengkel? Tidak kah semua itu fatal? ${ }^{18}$

Terlepas dari gambaran cerah atau suram yang ditampilkannya, sains dan teknologi selalu membentangkan sebuah 'kemungkinan dunia' (the possible world) atau sebuah 'masa depan imajiner' (imaginary future), yaitu imajinasi tentang sebuah masyarakat masa depan yang dibangun melalui kekuatan sains dan teknologi. Sains dan teknologi berperan besar dalam mengkonstruksi sebuah arsitektur 'realitas' yang diimajinasikan (imagining reality), meskipun kerap sekali realitas yang dikonstruksi oleh sains dan teknologi tidak seperti yang dibayangkan, karena berbagai ekses buruk yang dihasilkannya.

Ada tiga kecenderungan utama pemikiran tentang sains dan teknologi dalam perannya membangun sebuah 'rumah' (oikos) atau 'tempat' (topos) bagi masyarakat manusia, yaitu: 1) utopianisme (utopianism) sebagai pandangan optimis tentang peran positif sains dan teknologi, 2) distopianisme (dystopianism), sebagai pandangan pesimis tentang sains dan teknologi, dan 3) 'hiper-topianisme' (hypertopianism), sebagai pandangan 'fatalis' tentang sains dan teknologi. ${ }^{19}$

Pertama, 'utopianisme', sebagai sebuah kecenderungan pemikiran tentang sebuah 'masyarakat tanpa cela' (perfect society) di masa depan dan peran sentral sains dan teknologi dalam membangunnya. 'Utopia' dalam bahasa Yunani berarti 'tak-bertempat'. Thomas More menggunakan istilah 'utopia' untuk menggambarkan sebuah masyarakat imajiner yang berada di sebuah tempat yang jauh, sebagai model kehidupan masyarakat masa depan yang demokratis dan tanpa kelas, dengan orang-orang yang bijak. 'Utopia' menjadi sebuah istilah generik untuk melukiskan segala bentuk narasi yang menceritakan sebuah komunitas di masa depan di mana segala sesuatu berlangsung indah, menyenangkan dan tanpa cela. Marshal McLuhan, misalnya, secara optimis melihat teknologi sebagai sebuah utopia 'perpanjangan manusia' di masa depan. Pandangan optimistik semacam ini diperlihatkan pula oleh berbagai pemikir, seperti Francis Bacon, New Atlantis (1624), Herman Kahn, The Next 200 Years (1976) sampai Howard Rheingold, Virtual Reality (1993). ${ }^{20}$

\footnotetext{
18 Jean Baudrillar, The Ecstasy of Communication, Semiotext(e), 1988, hal 94-95.

${ }_{19}$ Yaraf Amir Piliang, Sastra dalam Hiper Sains, Jakarta, Harian Kompas, 3 Agustus 2017, hal 2

20 ibid., hlm 2
} 
Para pemikir cyberspace, seperti John Perry Barlow, Jaron Lanier, Mark Pesce dan Timothy Leary, mengembangkan pandangan utopianisme yang lebih ekstrim, yaitu sebuah keyakinan, bahwa segala keterbatasan, hambatan dan kekurangan manusia (fisik, psikis, spiritual) dapat diatasi melalui kekuatan sains dan teknologi, khususnya teknologi realitas virtual (virtual reality), yang dapat menawarkan sebuah 'dunia baru', yang sepenuhnya dibangun secara artifisial (artificial reality)-inilah pandangan teknoromantisisme (techno-romantism). Kemajuan sains dan teknologi mutakhir: teknologi informasi, rekayasa molekul, bioteknologi, nanoteknologi, dan pemrograman kuantum-digital dapat menciptakan di masa depan 'manusia baru' dan 'realitas baru', yang dibentuk oleh tubuh baru yang bersifat artifisial (artifisial body), yaitu tubuh-tubuh virtual.

Kedua, distopianisme (dystopianism), sebagai pandangan pesimisskeptis tentang sains dan teknologi. 'Distopia' adalah sebuah tempat atau kondisi yang di dalamnya segala sesuatu dilukiskan tampil dalam kondisi seburuk-buruknya. Visi distopia tentang masa adalah lukisan tentang masalah-masalah serius yang ditimbulkan oleh perkembangan sains dan teknologi dan ketidakmampuan manusia mengatasi dan menanggungkan setiap bahaya, risiko dan bencananya. Untuk itu, harus ada upaya serius untuk membendung bahkan menghentikan pertumbuhan sains dan teknologi, yang bila tidak dilakukan akan membawa pada bencana dan kehancuran manusia (catasthrope). Perkembangan sains dan teknologi yang 'melampaui' menyediakan terlalu banyak fungsi dan produk, yang semakin menjauhkan manusia dari alam. Teknologi informasi, misalnya, menjadikan setiap individu sebagai subyek yang berjarak dengan dunia realitas, semacam 'penjarakan pengalaman' (distanciation). Sehingga, ketimbang menghasilkan kepuasan dan kebahagiaan, teknologi sebaliknya menciptakan 'ketakpuasaan' dan 'kesadaran tak bahagia' (unhappy consciousness) yang abadi. Subyek dari hari ke hari terpasung ke dalam seduksi teknologi (seduction) dan 'terbenam' di dalam strukturnya, yang mengkerdilkan ruang untuk berpikir dan refleksi. ${ }^{21}$

Ketiga, 'hiper-topianisme' (hyper-topianism), yaitu pandangan tentang lukisan dunia yang kehilangan batas, kategori dan ukuran. 'Hiper-topia' dapat dijelaskan sebagai 'tempat yang melampaui', yang mendekonstruksi segala batas, definisi dan kategori-ketegori yang ada. Bila pandangan utopianisme mempunyai definisi dan batas-batas tentang apa yang disebut 'baik', 'sempurna', 'bahagia'; dan, pandangan distopia mempunyai definisi dan batasbatas tentang apa yang disebut 'buruk', 'merusak' dan 'bencana'; pandangan hiper-topianisme tidak mempunyai definisi dan ukuran-ukuran itu, disebabkan ia dibangun oleh prinsip 'fatalisme' (fatalism). ${ }^{22}$

21 ibid., hlm 3

22 ibid., hlm 3 
Jean Baudrillard adalah salah satu pemikir 'hiper-utopis' macam ini, yang melihat perkembangan sains dan teknologi melalui pandangan fatalis. Sains dan teknologi dipandang telah berkembang ke arah kondisi 'melampaui' (hyper), yang tidak menyediakan lagi ruang untuk refleksi di dalamnya. Manusia tunduk pada kekuasaan sains dan teknologi, menempatkan dirinya di hadapan produk-produknya sebagai 'mayoritas yang diam' (the silent majorities), dan menjadi bagian dari setiap struktur yang diciptakannya. ${ }^{23} \mathrm{Ke}$ manapun arah perkembangan sains dan teknologi, meskipun ke arah bencana (catasthrope) dan penghancuran diri sendiri (self-destruction), manusia tidak mungkin melepaskan diri darinya, di dalam semacam sebuah 'keniscayaan' (the necessity of technology), sehingga satu-satunya posisi yang tersedia adalah 'menikmati' semuanya, sebelum bencana itu datang.

\section{PENUTUP}

Berbagai arus pemikiran yang diteliti penulis dari sejumlah literatur dalam bidang ini memperlihatkan kecendrungan para pemikir lebih banyak menyoroti aspek negatif dari kemajuan teknologi komunikasi mutakhir. Hal yang sama juga tergambar dalam tulisan ini. Penggambaran masa depan yang suram tentang teknologi komunikasi dalam tulisan ini bisa dilihat positif, bahwa, ia memberikan kita sebuah peta kecendrungan dari semangat kemajuan itu, sebagai sebuah "sistem peringatan jauh-jauh hari" yang memberikan pemetaan, ramalan, dan kemungkinan masa depan dengan berangkat dari tren sosial,budaya dan teknologi masa kini dapat membantu kita membaca konstelasi, situasi dan dampaknya.

\section{DAFTAR PUSTAKA}

Aswan, Social Control and New Media: A Study of the use of Facebook by the Student of Makassar to Control the Public Policy, Tesis Pasca Sarjana di Universitas Hasanuddin, Makassar, 2011, hal 17

Douglas Kellner, Media Culture: Cultural Studies, Indentiti and Politics between the Moderen and the Postmodern, London and New York, Routledge, 1995, hal 1

23 Jean Baudrillard, America (London: Verso, 1991), hal. 125

Amerika, menurut Baudrillard, adalah sebuah model modernitas yang berkembang menuju titik 'ekstrim', yaitu ke arah modernitas radikal (radical modernity), yang merealisasikan dan mematerialisasikan segala sesuatu yang selama ini dianggap bersifat utopis. Di Amerika segala bentuk utopia telah tercapai, telah direalisasikan. Tak ada lagi daerah angan-angan, tanah impian, atau horizon pengharapan, karena segala hal diasumsikan bisa dicapai, direalisasikan, dimaterialisasikan. Segala bentuk metafisika, transendensi, fiksi, mimpi, halusinasi bisa dimaterialisasikan lewat kemampuan teknologi simulasi, yang menciptakan sebuah paradoks utopia atau 'hiper-utopia'. Artinya, bila utopia telah tercapai (di Amerika) maka sesungguhnya ia tidak lagi utopia. Bila impian telah menjadi realitas, maka ia bukan lagi impian-the death of utopia. 
Jean Baudrillard; Beyond the Vanishing Point of Art," terj. Paul Foss, dalam P. Taylor, ed., Post-Pop Art, Cambridge: MIT, 1987, 69

Jean Baudrillard, The Ecstasy of Communication, Semiotext(e), 1988, hal 95-95.

Jean Baudrillard, America (London: Verso, 1991), hal. 125

Marshall McLuhan, Understanding Media: The Extensions Of Man, Routledge Classics, London, 1964, hal 248

Martin Heidegger, The Age of the World Picture 1995, hal 56

Yaraf Amir Piliang, Sastra dalam Hiper Sains, Jakarta, Harian Kompas, 3 Agustus 2017, makalah yang disampaikan dalam Diskusi Sastra Seri 12 "Sains dan Sastra", diselenggarakan oleh Bale Sastra Kecapi, Harian Umum Kompas \& Bentara Budaya, Jakarta, 3 Agustus 2007, hal 1

Yasraf Amir Piliang, Post-Realitas; Realitas Kebudayaan dalam Era PostMetafisika, Penerbit Jalasutra, Yogyakarta, 2004, hal 40

Yasraf Amir Piliang, Merayakan Abnormalitas: Identitas di Zaman Pluralisme Kebudayaan, dalam Jurnal Kalam, Jakarta 1995, hal 90

Yasraf Amir Piliang, Tamasya Diantara Keping-Keping Masa Lalu, Titik Balik Modernitas, dalam Jurnal Kalam, Jakarta 1994, hal 106 